\title{
A satisfação de usuários da informação jurídica: estudo na biblioteca da OAB /SC
}

Cirlei Oraci Dias de Campos

Estudante do curso de Bacharelado em Biblioteconomia da Universidade Federal de Santa Catarina (UFSC)

Emanoel Quartiero da Silva

Bolsista de Iniciação Científica CNPq do curso de bacharelado em Biblioteconomia da Universidade Federal de Santa Catarina (UFSC)

Marli Dias de Souza Pinto

Doutora em Engenharia de Produção pela Universidade Federal de Santa Catarina (UFSC).Professora do Departamento de Ciência da Informação .Coordenadora do Curso de Graduação em Biblioteconomia da UFSC

http://dx.doi.org/10.1590/1981-5344/2366

Este artigo encontra-se fundamentado em um caso de pesquisa com usuários da informação jurídica, levantamento que propôs investigar o grau de satisfação dos usuários da Biblioteca Dr. João Baptista Bonnassis, situada na Ordem dos Advogados do Brasil (OAB) do Estado de Santa Catarina, em relação ao acervo e aos serviços prestados. Para tanto, a pesquisa objetiva identificar o perfil dos usuários da Biblioteca; conhecer a opinião desses quanto à relevância e suficiência dos itens do acervo; verificar o conhecimento dos usuários quanto aos serviços existentes na unidade; descrever os serviços utilizados pelos usuários; detectar possíveis carências do acervo e dos serviços prestados. A pesquisa possuiu caráter exploratório e descritivo, cujo procedimento técnico é um estudo de caso. O instrumento empregado para coleta de dados foi um questionário, destinado aos 61 usuários que compõem o corpus de pesquisa. Desse número, 42 responderam as questões, os quais representam usuários internos e externos e encontram-se envolvidos comumente a área de Direito. Entre as principais constatações estão as de que $90,47 \%$ dos investigados avaliam o acervo da unidade como muito 
bom, bom ou excelente, e medido pelos mesmos critérios, $85,71 \%$ dos respondentes afirmam que os serviços prestados atendem suas necessidades. Conclui-se que a maioria dos serviços é conhecida e utilizada, mensalmente, pelos usuários, bem como o acervo vem atendendo-os de forma satisfatória.

Palavras-chave: Estudo de usuários; Satisfação de usuários; Usuários da informação jurídica; Biblioteca jurídica.

\section{The satisfaction of users of juridical information: study in the OAB/SC library}

This article is based on a case study with users of juridical information, a survey that proposed to investigate the level of satisfaction of users of the Dr. João Baptista Bonnassis library, located at the Order of Attorneys of Brazil $(O A B)$ of the state of Santa Catarina, regarding the collection and the services provided. For such, this study aimed to identify the profile of the library users; to know their opinion on the relevance and sufficiency of the items of the collection; to check their knowledge about existing services in the unit; to describe the services used by users; to detect possible deficiencies of the collection and the services provided. The research has a exploratory and descriptive nature, whose technical procedure is a case study. The instrument used for data collection was a questionnaire for the 61 users that make up the corpus of research. 42 of these answered the questions, which represent internal and external users and are commonly involved with the law area. Among the main findings are that $90.47 \%$ of the investigated evaluates the unit's collection as very good, good or excellent and, measured by the same criteria, $85.71 \%$ of those interviewed stated that the services provided meet their needs. It concludes that most services are known and used monthly by users as well as the collection is the meeting satisfactorily.

Keywords: User study; User satisfaction; Users of juridical information; Juridical library.

Recebido em Aceito em 21.03.2015 Aceito em 16.08.2015 


\section{Introdução}

Historicamente, a grande preocupação das Unidades de Informação (UI) sempre esteve atrelada ao conteúdo, ao desenvolvimento de coleções, aos sistemas de informação sem pensar muito se determinado usuário ou comunidade, faria a devida utilização daquilo que estava sendo oferecido. Segundo Ferreira (1995, p. 3-4), o usuário da informação é visto apenas como um dos integrantes do sistema, mas não como a "razão de ser" do serviço, pois os sistemas de informação vêm sendo planejados por meio das tecnologias usadas para sua implementação ou do conteúdo da informação a ser inserida. Assim, o usuário é colocado na posição passiva de ter de se adequar aos mecanismos dos serviços de recuperação da informação, ao invés desses mecanismos serem adaptados às suas características particulares.

Para Guinchat e Menou (1994, p. 481), "o usuário é um elemento fundamental de todos os sistemas de informação, pois a única justificativa das atividades destes sistemas é a transferência de informações entre dois ou mais interlocutores distantes no espaço e no tempo". Esses autores acrescentam que "o usuário deve ser a base da orientação e da concepção das unidades e dos sistemas de informação, a serem definidos em função de suas características, de suas atitudes, de suas necessidades e de suas demandas" (GUINCHAT; MENOU, 1994, p. 482).

Mas essa realidade vem mudando, apesar de não ser empregada de forma efetiva em todas as UI, sobretudo nas bibliotecas, e de se verificar grande preocupação com o conteúdo e os sistemas de informação, que é algo ainda muito arraigado, percebe-se que o que vem forçando essa mudança é a procura pela qualidade dos serviços oferecidos, algo que obteve uma maior evidência com a sociedade globalizada e com o surgimento das tecnologias de informação e comunicação, e que levou os profissionais da área biblioteconômica a repensarem suas funções e os serviços que prestavam nas bibliotecas. Conforme Silva (2012, p. 12), "é papel do centro de informação e do profissional da informação atentar para as necessidades de informação do usuário, pois não é qualquer serviço que irá satisfazer suas necessidades".

Estudar e conhecer usuários de informação ou uma comunidade compõe uma das formas importantes para verificar a satisfação destes, mediante alguns aspectos, incluindo a prestação de serviços. Dessa forma, foram elencados dois aspectos para a realização desta pesquisa referentes a acervo e serviços prestados -, que serão discorridos nos objetivos apresentados em seguida. A aplicação do estudo se deu com usuários em uma biblioteca especializada de cunho jurídico.

O interesse de realizar investigação em uma biblioteca especializada surge da necessidade de mais estudos voltados ao conhecimento de públicos específicos, seu comportamento e relação com a instituição mantenedora. Bibliotecas jurídicas se constituem em um ambiente para atender um público específico, desse modo seu acervo e serviços necessitam de constantes verificações para que estejam sempre constituídos por itens relevantes e atualizados, atendendo, assim, as 
necessidades informacionais dos seus usuários. É possível afirmar que, nesse espaço, o acervo e os serviços prestados exercem papel fundamental para amparar demandas na área jurídica, pois fornecem subsídios para a geração de conhecimentos e auxílio à vida profissional.

A pesquisa foi realizada na Biblioteca João Baptista Bonnassis, que pertence à entidade Ordem dos Advogados do Brasil (OAB). A OAB foi criada em 1930, com o objetivo de defender a constituição, a ordem jurídica do estado democrático de direito, os direitos humanos, a justiça social e a pugnação das leis, pela rápida administração da justiça e pelo aperfeiçoamento da cultura e das instituições jurídicas, além de promover a representação, a defesa, a seleção e a disciplina dos advogados em toda a República Federativa do Brasil, cabendo a ela representar os interesses gerais da classe dos advogados e dos indivíduos, relacionados com 0 exercício da profissão (ORDEM DOS ADVOGADOS DO BRASIL - OAB, 2014).

A Biblioteca, em questão, foi inaugurada no dia 11 de agosto de 1992, recebendo o nome do ex-presidente e ex-conselheiro Dr. João Baptista Bonnassis, como homenagem por este ter doado grande parte do acervo que a compõe. Suas atividades tiveram início na Rua Padre Miguelinho, 58, Centro, Florianópolis, cujo local é o mesmo onde hoje funciona a Casa da Memória. Em 1995, a Biblioteca foi transferida para seu endereço atual junto ao novo prédio da OAB/SC, Rua Paschoal Apóstolo Pítsica, 4860, Agronômica, Florianópolis. Seu horário de funcionamento é de segunda-feira a sexta-feira, das 8 hs às $19 \mathrm{hs}$. Tal unidade foi criada com o objetivo de oferecer suporte informacional na área jurídica, procurando satisfazer as necessidades informacionais dos usuários, e facultar à Ordem dos Advogados do Brasil - Seccional Santa Catarina, a integralização dos recursos bibliográficos e informativos indispensáveis à realização de sua missão e dos seus objetivos. A instituição tem como missão oferecer suporte e prestar serviços que satisfaçam as necessidades informacionais da entidade mantenedora, seus membros, servidores, advogados e estagiários nela inscritos; visando o uso, a geração e a disseminação da informação jurídica. A visão da unidade é ser uma biblioteca de excelência na gestão e disseminação da informação jurídica.

O contexto apresentado suscitou a seguinte questão: qual o grau de satisfação dos usuários da Biblioteca Dr. João Baptista Bonnassis, em relação ao acervo e aos serviços prestados? Assim, determinou-se como objetivo geral, investigar o grau de satisfação dos usuários da Biblioteca Dr. João Baptista Bonnassis, em relação ao acervo e aos serviços prestados, e como objetivos específicos: identificar o perfil dos usuários da Biblioteca; conhecer a opinião dos usuários da Biblioteca quanto à relevância e suficiência dos itens do acervo; verificar a ciência dos usuários quanto aos serviços existentes na unidade; descrever os serviços utilizados pelos usuários; detectar possíveis carências do acervo e dos serviços prestados. 


\section{A pesquisa e o estudo de usuários}

No período contemporâneo, o conjunto de atividades que constitui a ciência, intenciona visualizar o ambiente, as relações sociais e suas culturas, de forma a promover o bem-estar humano, a melhoria dos seus vínculos e do relacionamento com a natureza. Para que se cumpra esse objetivo e, consequentemente, favoreça avanços, torna-se necessário seguir fazendo o uso da ferramenta originada nos tempos passados, e que ainda hoje se mantém como a principal forma de gerar o conhecimento científico, que é a pesquisa.

$\mathrm{O}$ ato de pesquisar ou investigar corresponde ao surgimento de determinados problemas e a busca de soluções para as questões levantadas. Por meio de diferentes métodos procuram-se, constantemente, averiguar temas sobre diferentes âmbitos, de forma a promover o aprimoramento de assuntos, a resolução de conflitos, a continuidade do intercâmbio de ideias, a melhoria do bem-estar, entre outras ações.

A explanação realizada anteriormente, que toma como base o princípio da ciência, objetiva evidenciar a importância da pesquisa para o desenvolvimento de diferentes meios, dentre os quais se destaca, essencialmente, o meio social. Tal atividade, além de sustentar o meio científico, contribui para o estabelecimento de melhorias e interações na sociedade, fundamentando relações básicas cotidianas e o exercício de profissões. Dessa forma, a constituição e existência de uma Unidade de Informação (UI) também pode estar aliada à realização de pesquisas.

As unidades de informação - bibliotecas, museus, arquivos, centros de documentação - responsabilizam-se pelo tratamento da informação produzida, por meio da formação de acervos, compilação de informações contidas em diferentes suportes, entre outras funções. Ressalta-se, porém, que a estruturação e existência de itens informacionais somente obtêm valor quando utilizados pelas pessoas. Com isso origina-se o motivo central de existência dos centros que abrigam o conhecimento global: a utilização da informação por usuários.

Unidades como bibliotecas, baseiam-se, substancialmente, na disponibilização da informação e prestação de variados serviços a diferentes tipos de usuários ao redor do mundo. Partindo-se desse princípio, torna-se claro que os profissionais da informação e os espaços onde atuam passam a manter contato com pessoas de diferentes idades, hábitos, culturas, escolaridades e ensejos, o que garante uma multiplicidade de perfis, ideias e necessidades de informação. Frente a isso, faz-se imprescindível que esses agentes conheçam as pessoas a que se direciona sua UI e que verifiquem do que precisam e o que pensam tais indivíduos que, mesmo estando em um contexto semelhante e tendo em comum a necessidade de informação, são seres cognitivos, dotados de particularidades. Uma das formas empregadas para que isso seja possível é a realização de estudos de usuários.

Estudos de usuários são empregados, predominantemente, em investigações com profissionais e o público de bibliotecas. Baseiam-se na 
busca pelo conhecimento sobre as pessoas que frequentam - ou que poderiam frequentar - esse tipo de unidade, por meio da identificação dos seus perfis, da verificação de suas necessidades ou da sua satisfação quanto a determinadas questões que envolvem o cotidiano de uma biblioteca e seu funcionamento. Com isso, busca-se conhecer essas pessoas e o que pensam, em nível coletivo e também individual. $O$ estudo de usuários trata-se, conforme Araújo (2010, p. 25),

[...] de um campo desenvolvido ao longo de algumas décadas, com forte caráter empiricista, voltado para a aplicação de métodos prioritariamente quantitativos na busca de padrões e regularidades do comportamento dos usuários para 0 estabelecimento de leis "científicas" sobre o uso da informação.

A aplicação de métodos quantitativos, como mencionado por Araújo, representou a forma precursora adotada nas investigações com usuários, o que, segundo Baptista e Cunha (2007, p. 170), teve "um papel preponderante durante as décadas de 1960 a 1980" e "seu uso intensivo teve por objetivo garantir uma maior precisão na análise e interpretação dos resultados, tentando, assim, aumentar a margem de confiabilidade quanto às inferências dos resultados encontrados".

A realização de estudos de usuários teve seu início em um período considerado recente, o qual registrou experiências expressivas a partir da metade do século XX. Figueiredo (1994) relata o surgimento de trabalhos significativos e formalizados, em tal âmbito, em três momentos diferentes. O primeiro deles ocorreu entre 1948 e 1965, e buscava saber como se dava o uso da informação por cientistas e engenheiros. Nesse período, destacou-se a apresentação de trabalhos na Conferência da Royal Society, de Londres, em 1948, e a Conferência Internacional de Informação Científica, em Washington, no ano de 1958. O segundo momento notável para as produções que levavam em conta necessidades de usuários, ocorreu a partir de 1965, trazendo o uso de diferentes técnicas voltadas à observação indireta, de maneira a estudar características particulares do comportamento de usuários, por meio de atividades como a análise de citações e verificações de compilações estatísticas. E o terceiro período, ocorrido na década de 70, fez uso de estudo sociológico e concebeu investigações com pessoas inseridas em áreas como ciências sociais e humanidades, de forma ampla e exploratória (FIGUEIREDO, 1994).

Ao longo das décadas, a realização de trabalhos sobre usuários fez surgir tendências e semelhanças na forma como eram executadas pesquisas direcionadas a essa temática. Com isso, o conjunto de estudos produzidos sinalizou distinções que patrocinaram a formação de diferentes métodos. Destaca-se o surgimento de duas importantes abordagens, que guiaram e permearam as pesquisas com usuários da informação: a abordagem tradicional e a alternativa. Conforme Dervin e Nilan (1986), o princípio tradicional corresponde a estudos direcionados sob a ótica do 
sistema de informação. Quanto a isso, Ferreira (1997, p. 4) descreve que esses "são voltados ao conteúdo" sendo "estudos relacionados às linhas temáticas de interesse de grupos de usuários, sempre baseados nos modelos tradicionais de classificação do conhecimento". No que se refere à atuação e complexidade de averiguação dos elementos que compõem determinadas comunidades de usuários nesse tipo de estudo, a autora relata que a...

Abordagem tradicional não tem examinado os fatores que geram o encontro do usuário com os sistemas de informação ou as consequências de tal confronto. Limita-se à tarefa de localizar fontes e informação, desconsiderando as etapas de interpretação, formulação e aprendizagem envolvidas no processo de busca de informação. O aumento no acesso à vasta quantidade de informação requer serviços que se centrem no significado da busca mais do que meramente na localização da fonte (FERREIRA, 1997, p. 5).

Frente a isso, a busca pela averiguação do comportamento de usuários da informação passou a contar com alicerces alternativos, os quais visam proporcionar a captação de aspectos não explorados na abordagem tradicional. De acordo com Dervin e Nilan (1986), a abordagem alternativa está fundamentada sob a ótica do usuário, o que significa um aprofundamento nas questões voltadas a esse indivíduo. Esses autores apontam características que compõem essa fundamentação de pesquisa, que envolve observar o ser humano como sendo construtivo e ativo; considerar o indivíduo como sendo orientado situacionalmente; visualizar holisticamente as experiências do indivíduo; focalizar os aspectos cognitivos envolvidos; analisar sistematicamente a individualidade das pessoas; e empregar uma maior orientação qualitativa.

A forma de obtenção e tratamento dos resultados são elementos que distinguem os princípios tradicionais e alternativos. Os primeiros apresentam-se de forma objetiva, prezando, geralmente, por métodos quantitativos, enquanto que os segundos, passam a se utilizar da subjetividade para conhecer determinados contextos, o que condiz ao emprego de métodos qualitativos. Durante muito tempo, a pesquisa quantitativa representou a principal tipologia adotada, mas isso veio mudando ao longo das últimas décadas, com a percepção da importância da pesquisa qualitativa.

A escolha do tipo de pesquisa ou sua abordagem busca adequar-se aos objetivos definidos por quem deseja efetuá-la, contudo, salienta-se que todas as maneiras de realização de pesquisas com usuários da informação compactuam um mesmo objetivo: 0 de conhecer características de um conjunto de usuários inseridos em um meio. Tais trabalhos descrevem, conforme o enfoque, determinada realidade, apontando necessidades informacionais, a satisfação ou insatisfação 
desses indivíduos, quanto a certas questões envolvendo unidades de informação. Permitem detectar usuários reais e potenciais, conhecer aspectos de perfil do público referido, suas expectativas e interesses, observar o comportamento, além de entender o significado que a informação tem para esses indivíduos. As informações obtidas também representam ferramentas importantes para a realização do planejamento de serviços de informação, para a avaliação, construção e desenvolvimento de acervos e políticas de acesso, identificação de demandas e solução de problemas. Isso permite que sejam adotadas as melhores maneiras para atender seu usuário e contribuir para o uso mais efetivo da informação (ARAúJO, 2010; CÉ; PEDRAZZI, 2011; COSTA; SILVA; RAMALHO, 2009).

Para o desenvolvimento de um estudo de usuários que seja satisfatório, devem ser observados e empregados elementos que viabilizem o atendimento do objetivo de pesquisa, dentre os quais se encontra o instrumento de coleta de dados. Ressalta-se que a escolha desse instrumento deverá ser compatível com o tipo de pesquisa proposta. Baptista e Cunha (2007) elencam como métodos mais utilizados na coleta de dados, o questionário, a entrevista, a observação e a análise do conteúdo. As autoras evidenciam que o questionário é a forma mais utilizada, pois apresenta vantagens como o de permitir atingir uma grande população, dar maior grau de liberdade e de tempo ao respondente e dar a possibilidade de serem menores as distorções, descritas por Cunha (1982).

Os locais de aplicação de pesquisas de cunho informacional podem ser variados. Não somente o público de Unidades de Informação pode ser submetido a verificações, mas toda a população, pois todos estão envolvidos com a informação, seja de maneira intensa ou em menor escala. Entretanto, estudos em Unidades de Informação são mais frequentes, pois o sucesso dos produtos e serviços oferecidos por essas instituições dependem diretamente da satisfação de pessoas específicas.

Como exemplo de estudo de usuários, está o desenvolvido por Costa e Ramalho (2010, p. 58), que afirmam que "diante da ansiedade da informação, tornou-se imprescindível o estudo da satisfação dos usuários, considerando a sua implicação na relação entre as crescentes necessidades individuais e institucionais de informação e a oferta de estoques de informação". Ainda enfatizam que "a satisfação promove o retorno vital ao novo ponto de mutação, ou seja, novamente a insatisfação" (COSTA; RAMALHO, 2010, p. 70).

Outro exemplo é o estudo de usuários, desenvolvido por Monteiro, Costa e Ramalho na biblioteca do Tribunal Regional do Trabalho da Paraíba, em que relatam que "a avaliação é um processo de suma importância para as unidades de informação, por meio da avaliação é possível identificar, mensurar e diagnosticar possíveis inconsistências/falhas nos produtos e serviços ofertados" (MONTEIRO; COSTA; RAMALHO, 2014, p. 22).

Reforça-se, ainda, a ideia de que bibliotecas representam as organizações que mais aderem a estudos de usuários, e que a 
heterogeneidade do público impulsiona o surgimento de bibliotecas especializadas em determinadas áreas, como o contexto jurídico retratado nesta pesquisa.

\section{Contexto de bibliotecas jurídicas}

A criação de bibliotecas especializadas decorreu da divisão do grande público por diferentes interesses, causada, principalmente, pela fragmentação da ciência em áreas do conhecimento. Nessas organizações, os princípios que norteiam sua existência estão centrados no tratamento de um determinado assunto ou em conjuntos de assuntos específicos. Dessa forma, os campos do saber que apresentam quantidades significativas de produções intelectuais, ou conteúdos que, de alguma maneira, se fazem relevantes a um grande número de pessoas, impulsionam a formação dessas unidades informacionais. É possível mencionar que entre as organizações que possuem notoriedade, no âmbito de organizações informacionais especializadas, estão as bibliotecas jurídicas.

Bibliotecas Jurídicas representam os ambientes de informação em que estão inseridos registros que asseguram a ordem de uma nação. Essas instituições encontram-se inseridas em órgãos governamentais, escritórios de advocacia, universidades e outras entidades. Independente dos suportes contidos nesse meio - sejam eles papel, formato eletrônico e outros - tais espaços caracterizam-se pelo tratamento, manipulação e disponibilização da informação jurídica produzida no país. Os conhecimentos produzidos nessa esfera destinam-se, principalmente, a tomada de decisão por parte das pessoas que os utilizam para o exercício de suas profissões e, também, por todos os cidadãos interessados. Isso revela uma importante função dessas bibliotecas, que corresponde à ação de possibilitar que o público, em geral, esteja em contato com obras que possam ajudá-los a exercer sua cidadania. Miranda, D'Amore e Pinto (2013, p. 99) descrevem a informação jurídica como originada, fundamentalmente, por um tripé informacional distinto: Legislação, Doutrina e Jurisprudência, em que

Legislação é o conjunto normativo que regula a convivência social, elaborada pelo Poder Legislativo dos Municípios, Estados e União; a Doutrina é o conjunto de princípios expostos nas obras de direito, em que se firmam teorias ou se fazem interpretações sobre a ciência jurídica; e a Jurisprudência é a sábia interpretação e aplicação das leis a todos os casos concretos que se submetem a julgamento da justiça, que produz sentenças, no primeiro grau, ou acórdãos e súmulas, nos Tribunais.

As fontes de informação jurídica correspondem a quaisquer obras que tratem dos domínios relatados e, também, a itens relacionados. $A$ composição de acervos e coleções, formados por tais obras, implica 
experiência e competência para compilar os elementos que permitirão que usuários atinjam determinadas finalidades por meio das informações obtidas. Para que isso se realize de maneira satisfatória, faz-se imprescindível a atuação de um profissional bibliotecário. A boa condução de uma biblioteca jurídica está ligada ao trabalho desse agente, o qual garante que tal atividade seja realizada, assim como diversas outras desenvolvidas em prol da disseminação da informação.

O bibliotecário jurídico responsabiliza-se pela direção, coordenação e realização das operações de tratamento e difusão da informação jurídica na unidade onde atua. Entre essas operações estão a "reunião, análise e indexação da doutrina, da legislação" e "de todos os documentos oficiais e atos normativos ou administrativos" (ANTIEZA, 1979, p. 19); fornece a informação desejada por usuários, indicando os mecanismos para obtê-la, e funções como realizar listagens de sites e bases disponíveis na biblioteca; emprega softwares específicos para gerenciamento de acervo; localiza endereços eletrônicos e informações relevantes a determinados assuntos; efetua a disseminação seletiva da informação; confere periodicamente a legislação vigente (OLIVEIRA, 2013; REZENDE; MACHADO, 2000); faz a divulgação do acervo e de serviços prestados; monta bibliografias; além de trabalhar nas políticas de indexação e de desenvolvimento de coleções, possuindo a ciência de que está lidando com objetos informacionais que sofrem constantes desatualizações, as quais atingem o tripé informacional - formado por Legislação, Doutrina e Jurisprudência. Quanto a isso, Pinho e Barbosa (2011, p. 52) mencionam que "as mudanças se iniciam na legislação e trazem consigo as modificações na jurisprudência".

Para que esse agente consiga desempenhar todas as suas funções de maneira eficiente, torna-se necessária a busca pela efetivação de algumas ações. Entre elas, destacam-se medidas como atualizar-se constantemente; conhecer os tipos de documentos jurídicos; saber lidar com as tecnologias; conhecer a terminologia jurídica; estar aberto ao recebimento de sugestões de usuários; trabalhar junto a outros profissionais da área quando necessário; e, conforme Silva (2005, p. 24), "estar atento à sua área de atuação, buscando sempre novos conhecimentos que agreguem valor ao exercício de suas competências através de uma educação continuada no exercício de sua profissão", e embora não existam cursos intensivos à formação de profissionais bibliotecários jurídicos, eles devem buscar outras modalidades de cursos, participar de eventos na área, ou até mesmo, ingressar em um curso de Direito. No texto de Silva (2005, p. 26) está contida uma listagem de competências de um bibliotecário jurídico, elaborada pela American Association of Law Libraries (AALL), dentre as quais inclui:

Entender e apoiar a cultura e o contexto da biblioteca e da instituição mantenedora; demonstrar conhecimento do sistema legal e da profissão jurídica; Entender o contexto sócio-econômico e político que embasa o sistema legal existente; Exibir qualidade de liderança incluindo pensamento 
crítico, administração de risco e criatividade, independente de sua posição na estrutura administrativa; exibir compreensão da importância da multidisciplinaridade dos programas e projetos dentro da organização; dispor de habilidades de comunicação e ser capaz de promover a biblioteca e defender suas necessidades, perseguir ativamente o desenvolvimento pessoal e profissional pela educação continuada.

Após o reconhecimento do agente que garante a disseminação da informação jurídica, torna-se propício o reconhecimento dos agentes mencionados nesta explanação, como dependentes dos itens informacionais de uma biblioteca para o exercício de suas profissões e, também, das demais pessoas interessadas nos conhecimentos gerados nesse meio. Os usuários reais de uma biblioteca jurídica podem ser pesquisadores, professores, estudantes de direito, advogados, juízes, desembargadores, magistrados, litigantes e, até mesmo, deputados, senadores, ministros, assessores de ministros e o presidente da república, conforme as categorias de usuários identificadas por Alpízar, Lidiette Diez e Rojas (1991) ${ }^{1}$ e Oliveira (2013).

A partir do exposto, tornou-se possível perceber a importância da biblioteca jurídica para seus usuários e do bibliotecário para a condução de suas atividades. Com a constatação de que os usuários representam o motivo que assegura a continuidade desse tipo de unidade de informação, torna-se incontestável a afirmação de que é a satisfação das pessoas que frequentam ou utilizam seus serviços, o motivo central de existência dessa organização, e que para que isso ocorra, o profissional bibliotecário deve conhecer o grau de contentamento,identificar carências e saber quais são suas necessidades. Dessa forma, a principal maneira de inteirarse dessa realidade é por meio da realização de estudos de usuários.

\section{Procedimentos metodológicos}

A pesquisa possui caráter exploratório e descritivo, cujo procedimento técnico é um estudo de caso. A análise dos dados se configura com abordagem qualitativa e quantitativa. Inicialmente, foi realizada uma visita técnica, a fim de conhecer a Biblioteca Dr. João Baptista Bonnassis, pertencente à Ordem dos Advogados do Brasil (OAB/SC), que culminou na solicitação de consentimento da bibliotecária para execução da pesquisa nessa biblioteca. Em um segundo momento, foi confeccionado o instrumento de coleta de dados, questionário, formado por 15 perguntas, sendo 7 fechadas, 5 abertas e 3 mistas, e aplicado no horário integral de atendimento da biblioteca (das $8 \mathrm{~h}$ às $19 \mathrm{~h}$ ). Sendo que, para sua confecção foram necessárias algumas informações referentes à

\footnotetext{
${ }^{1}$ Categorias apresentadas na obra Información Jurídica, resultante do Proyecto Fortalecimiento de Bibliotecas Jurídicas en América Latina, por iniciativa do Instituto Latinoamericano de las Naciones Unidas para la Prevención del Delito y el Tratamento del Delincuente (ILANUD) e da Universidad de Costa Rica.
} 
instituição, que foram obtidas por meio do contato com a bibliotecária da unidade.

O corpus da pesquisa é composto por 61 usuários da biblioteca, sendo 29 usuários internos que fizeram uso dos serviços da unidade nos últimos dois anos e que ainda fazem parte do quadro de funcionários, com cadastro para empréstimo de materiais e 32 usuários externos, sendo esse número correspondente à média da frequência semanal. Buscou-se trabalhar com uma média semanal, devido haver certa regularidade na presença dos usuários externos.

O questionário foi encaminhado para o e-mail da biblioteca no dia 3 de novembro de 2014, para que a bibliotecária pudesse direcioná-lo aos usuários internos e, também, foi deixado na unidade no período de 3 a 14 de novembro de 2014, sob a forma impressa, para preenchimento dos usuários externos. Previamente a isso, em um dos dias da semana anterior, foram escolhidos usuários para preenchimento de 5 questionários, configurando a realização de um pré-teste. Por meio do pré-teste não foi identificada necessidade de alteração das questões e, assim, todas foram mantidas.

Dos 61 possíveis respondentes (32 externos e 29 internos), 42 responderam ao questionário (32 externos e 10 internos).

\section{Resultados}

A Biblioteca contém acervo especializado na área jurídica, composto por, aproximadamente, 4330 livros, sendo 1818 em processo de desbastamento, 30 títulos de periódicos com 2600 exemplares, multimeios como fitas de vídeo e CD-ROM totalizando 555 itens. Todo o acervo está disponível para uso: livros; periódicos; jornais diários; multimeios; e material de referência (dicionários e vocabulários jurídicos, códigos e enciclopédias jurídicas).

Os serviços prestados concentram-se em atendimento aos usuários com orientação e auxílio na consulta, respostas às questões de referência e orientação sobre utilização do material disponível; recuperação de informações de interesse do usuário, levantamento bibliográfico por assuntos específicos; terminais de computadores com acesso à internet e sistema de rede wireless; pesquisa e levantamento de legislação, jurisprudência, doutrinas dos Tribunais; disponibilidade dos principais jornais de Santa Catarina e de fora do Estado para consulta diária e empréstimo de materiais. Alguns serviços podem ser solicitados por telefone, e-mail ou pessoalmente.

O público que frequenta e/ou utiliza os serviços da unidade é composto por usuários internos e externos. Internos: membros da $\mathrm{OAB} / \mathrm{SC}$ (diretoria e conselheiros) e seus colaboradores. Externos: advogados e estagiários inscritos na $O A B$, estudantes e bacharéis em Direito e o público em geral.

O objetivo inicial foi identificar o perfil dos usuários da unidade e, para isso, perguntou-se o sexo, idade e grau de escolaridade. Foi identificado que a maioria dos usuários é do sexo feminino, 25 
respondentes, e 17 do sexo masculino. Quanto à idade, verificou-se que a maioria dos respondentes se encontra entre 31 a 40 anos, correspondendo a 20 usuários; houve empate entre as faixas etárias de 21 a 25 anos e de 26 a 30 anos, havendo 9 usuários para cada opção; e a faixa de idade acima de 40 anos se mostrou com o menor número de usuários, 4 respondentes. Os resultados apontam que a maioria, 59,52\% dos usuários, está fazendo alguma especialização na área de Direito, enquanto que $28,57 \%$ possuem o ensino superior completo e $11,9 \%$ estão cursando o nível superior. Perguntou-se qual curso superior o usuário já cursou ou está cursando, e obteve-se como resposta que os 42 respondentes cursaram ou cursam Direito. Desses, 3 sinalizaram que também já cursaram administração.

Por meio de consulta a literatura da área, pode-se constatar a relação existente entre necessidades informacionais e satisfação de usuários, pois como afirma Silva (2012, p. 112) "a satisfação dos usuários só pode ser efetivamente concretizada quando do conhecimento e contemplação das necessidades de informação". Dessa forma, os resultados, descritos a seguir, permitiram avaliar a satisfação do núcleo de usuários pesquisado, quanto aos aspectos propostos nos objetivos de pesquisa, implicando na compreensão do consequente atendimento das necessidades dos mesmos.

O segundo objetivo da pesquisa envolveu conhecer a opinião dos usuários da biblioteca quanto à relevância e suficiência dos itens do acervo. A primeira questão referia-se à atualização dos livros, periódicos, CD-ROM e outros materiais disponíveis para consulta, em que os usuários teriam que dar uma nota. A abordagem seguinte estava relacionada ao nível de conservação dos livros, periódicos, CD-ROM e outros itens disponíveis no acervo, nesse caso, os usuários teriam que apontar um conceito. $\mathrm{E}$, por fim, perguntou-se se o material disponível para pesquisa atendia as necessidades informacionais dos usuários, em que responderiam com uma nota. Foram usados os conceitos ruim, regular, bom, muito bom e excelente, cada um possui um valor numérico.

Percebeu-se que a maioria dos usuários, $40,47 \%$, atribuiu nota 4 para o acervo (muito bom), já $28,57 \%$ dos usuários atribuiu nota 3 (bom), 21,43\% aponta a nota 5 (excelente) e apenas 7,14\% avaliaram com a nota 2 (regular). Dentre os respondentes, um não respondeu à pergunta.

Quanto ao nível de conservação do acervo, dos cinco conceitos usados para avaliação, apenas três foram sinalizados (bom, muito bom e excelente). Verificou-se proximidade das respostas entre os que consideram o acervo excelente, $40 \%$, e os que acreditam que seja muito bom, $38 \%$. Os outros $22 \%$ consideraram o acervo bom.

Ao se perguntar se os materiais disponíveis para pesquisa atendiam as necessidades dos usuários, a maior parte dos usuários, 40,47\%, apontou a nota 4 (muito bom) para o atendimento das necessidades informacionais por meio do uso dos materiais de pesquisa, enquanto que $26,19 \%$ considera a nota 5 (excelente) para o atendimento, 21,43\% deu nota 3 (bom) e 11,9\% avalia com a nota 2 (regular). 
Para atender ao terceiro objetivo da pesquisa - verificar o conhecimento dos usuários quanto aos serviços existentes na unidade foram elaboradas duas perguntas, ambas com a possibilidade de marcação de várias opções. Buscou-se saber quais dos serviços disponíveis na unidade, os respondentes utilizam e quais desconhecem.

Dessa forma, os resultados dos dados coletados mostraram que $88,1 \%$ dos usuários utilizam o serviço de consulta local, o segundo serviço mais usado foi o acesso à internet com 52,38\% de uso, o terceiro serviço usado é o empréstimo com $23,81 \%$ de uso, o quarto serviço é a solicitação de levantamento bibliográfico com $9,52 \%$ de utilização e a opção de pergunta aberta "Outros", obteve $4,76 \%$ de resposta. Nessa opção, dois respondentes informaram estudar na biblioteca e que nem sempre usufruem desses serviços e um deles mencionou fazer uso de impressão. Quanto à disparidade entre os valores, pode-se dizer que a consulta local se destaca, porque o acervo está disponível tanto aos usuários internos quanto externos e para chegar a ele terão que se deslocar até a biblioteca, o que não acontece com o acesso à internet, devido os usuários internos possuírem acesso à rede em suas salas, sendo mais usado pelo público externo. Com relação ao empréstimo, este está disponível somente para os usuários internos, motivo este da pouca utilização. A solicitação de levantamento bibliográfico parece ser um serviço pouco divulgado.

A grande maioria dos usuários, $57,14 \%$, tem ciência de todos os serviços oferecidos, há o desconhecimento entre o empréstimo e a solicitação de levantamento bibliográfico, cujo valor é de $21,43 \%$, e o acesso à rede obteve $2,38 \%$ de desconhecimento. Como mencionado anteriormente, o desconhecimento dos serviços de empréstimo e solicitação de levantamento bibliográfico se deve, ao primeiro, por ser apenas para os usuários internos e, ao segundo, por talvez, não ter muita divulgação.

Ao objetivo seguinte - descrever os serviços utilizados pelos usuários - perguntou-se com que frequência os usuários utilizavam os serviços prestados pela biblioteca.

Verificou-se que a maior parte dos usuários (10) utiliza os serviços da unidade de 3 a 4 vezes por semana, em segundo lugar estão os que usam de uma a duas 2 vezes por semana (9). Há valores iguais, 7 usuários responderam que usam os serviços 5 vezes por semana, 7 que usam uma vez por mês e 7 utilizam de 2 a 3 vezes por mês. Por fim, duas pessoas responderam usar os serviços raramente.

Solicitou-se, na segunda questão, que expressassem o número de vezes (mensal) de uso dos serviços. Essa pergunta possibilitava a marcação de várias opções. As respostas obtidas foram: Empréstimo - 3 usuários utilizavam de 1 a 3 vezes por mês; Consulta local ao acervo - 18 usuários utilizavam de 1 a 18 vezes por mês e 3 usavam 20 vezes por mês; Acesso à internet - 7 usuários usavam o serviço de 1 a 15 vezes por mês e 8 usavam de 20 a 30 vezes por mês; Solicitação de levantamento bibliográfico - uma pessoa respondeu usar o serviço 4 vezes por mês. 
Houve dois usuários que responderam com incoerência de valores e outros 5 assinalaram a opção "Não utilizo os serviços mensalmente".

O último objetivo da pesquisa buscou detectar carências do acervo e dos serviços prestados. Foram feitas 3 perguntas. Perguntou-se, inicialmente, se os serviços oferecidos atendiam as necessidades informacionais dos usuários. A partir das respostas obteve-se o seguinte resultado: 35 usuários disseram que suas necessidades são atendidas, 5 responderam que atende em parte, apenas um disse que não atende e um usuário não respondeu. Em seguida, foi perguntado se os usuários sempre encontravam o material que desejavam. Como resposta obteve-se: 22 respondentes disseram que sempre encontravam o que desejavam, 14 citaram que quase sempre são atendidos, 5 citaram que não são atendidos e um disse que o acervo poderia ter mais novidades.

Por último, foi deixado um espaço para que pudessem realizar críticas, sugestões quanto ao acervo e aos serviços prestados pela biblioteca. Dos respondentes, 19 deles contribuíram com elogios ou sugestões de serviços, melhorias do acervo e espaço. Muitos fizeram mais de um apontamento, sendo que foram agrupadas as opiniões semelhantes para facilitar a análise.

Quanto aos elogios, foi mencionado por dois usuários que o ambiente é silencioso, 6 disseram que o espaço é bem estruturado e/ou organizado, 3 citaram que o acervo é excelente, 4 usuários mencionaram que as bibliotecárias são excelentes ou atenciosas ou que se mostram prestativas no atendimento.

Em relação às críticas, um respondente citou que a unidade tem livros velhos e sem uso que poderiam ser descartados para ceder espaço para mesas de estudo; um outro também mencionou a ampliação do espaço físico para compor mais mesas de estudo; uma pessoa citou que os computadores deveriam se localizar em um local próximo, mas não na biblioteca; um deles citou a possibilidade de reprografia e dois outros usuários mencionaram a criação de uma sala reservada para estudo; 6 pessoas sugeriram que fosse disponibilizado o serviço de empréstimo para os usuários externos; um outro usuário mencionou que o empréstimo das obras poderia ser se dar nos fins de semana; um outro reclamou que 0 prazo de empréstimo é curto, geralmente de um dia; 9 pessoas citaram que o acervo poderia ser mais atualizado; uma outra citou ser necessário ampliar o acervo referente a concursos públicos e dois usuários citaram que não há disponibilidade de livros de todas as áreas.

É possível verificar que, talvez, essas últimas menções sejam comuns à realidade de outras bibliotecas no âmbito jurídico, tal como no exemplo do estudo de Pinho e Barbosa (2011, p. 59), em que perguntados de forma similar, os usuários da biblioteca da Procuradoria Regional da República $5^{a}$ Região apresentaram, como sugestão para modificação dessa biblioteca, a "ampliação do acervo de um modo geral, do acervo de livros mais atualizados e do acervo de exemplares mais procurados, melhor acervo de obras de estudo para concursos, periódicos", entre outros. 
Portanto, é possível perceber que as maiores carências são o acervo, que necessita fundamentalmente de atualização, e o serviço de empréstimo, que necessita de mudanças nos prazos e de ser, também, disponibilizado aos usuários externos.

\section{Considerações finais}

A realização de estudos com usuários em bibliotecas representa uma ação significativa ao desenvolvimento e continuidade dessas unidades informacionais. Tal atividade pode deter importância ainda maior em bibliotecas especializadas, pois devido a sua proposição existencial, a qual corresponde ao fornecimento de recursos informacionais, relativos a uma determinada área do conhecimento ou a outros âmbitos específicos, surgem diferentes demandas e, também, diferentes tipos de necessidades informacionais de usuários. Dessa forma, pesquisas com usuários da informação jurídica tornam-se imprescindíveis à adequação das bibliotecas que concebem esse tipo de informação ao seu público.

Frente a isso, esta pesquisa propôs investigar o grau de satisfação dos usuários da biblioteca Dr. João Baptista Bonnassis, situada na $\mathrm{OAB} / \mathrm{SC}$, sob os aspectos de seu acervo e serviços prestados. Acredita-se que os objetivos aqui propostos foram efetivados, podendo-se, dessa maneira, conhecer uma parcela representativa dos usuários que compõem a atual realidade dessa unidade de informação. A conclusão obtida, a partir da pergunta central que guiou esta verificação, foi a de que o público investigado está satisfeito com o acervo disponível e com os serviços prestados, o que traduz o atendimento de suas necessidades sob ambos os âmbitos. Entre outras conclusões importantes obtidas estão, quanto aos serviços, a constatação de que sua maioria é conhecida pelos usuários e que esses os utilizam mensalmente, sendo que a consulta local é a forma mais solicitada $e$, no que se refere ao acervo, verificou-se pluralidade na localização dos materiais desejados. Ainda assim, mesmo com as constatações obtidas e com os elogios ao ambiente e aos profissionais que trabalham na unidade, foram recebidas críticas e sugestões quanto ao empréstimo, atualização do acervo e aquisição.

Acredita-se que a unidade deva atentar para as críticas e sugestões recebidas de forma construtiva, de maneira a buscar, constantemente, a solução para possíveis carências e, junto à entidade superior, captar recursos quando necessário à geração de mudanças e desenvolvimento de determinadas atividades.

Sugere-se, portanto, que a biblioteca estudada, assim como as demais unidades ativas existentes no âmbito jurídico, realize, futuramente, novas pesquisas direcionadas a usuários, pois bibliotecas jurídicas, assim como outras modalidades de bibliotecas, possuem públicos e necessidades voláteis, estando em constantes mudanças e requerendo novas alternativas que satisfaçam eficientemente o desejo e a busca por informações. 


\section{Referências}

ANTIEZA, C. A. Documentação jurídica: introdução à análise e indexação de atos legais. Rio de Janeiro: Achiame, 1979.

ARAÚjO, C. A. Á. Estudos de usuários conforme o paradigma social da ciência da informação: desafios teóricos e práticos de pesquisa. Informação \& Informação, Londrina, v. 15, n. 2, p. 23-39, jul./dez. 2010.

BAPTISTA, S. G.; CUNHA, M. B. da. Estudo de usuários: visão global dos métodos de coleta de dados. Perspectivas em Ciência da Informação, Belo Horizonte, v. 12, n. 2, p. 168-184, maio/ago. 2007.

CÉ, G.; PEDRAZZI, F. Estudo de usuários como recurso para a difusão de um arquivo: o caso da Universidade Federal de Ciências da Saúde de Porto Alegre. Biblos: Revista do Instituto de Ciências Humanas e da Informação, v. 25, n. 2, p. 75-89, jul./dez. 2011.

COSTA, L. F. da; RAMALHO, F. A. Novas perspectivas dos estudos de satisfação de usuários. Encontros Bibli: Revista Eletrônica de Biblioteconomia e Ciência da Informação, Florianópolis, v. 15, n. 30, p. 57-73, 2010.

Disponível

em: <https://periodicos.ufsc.br/index.php/eb/article/view/15182924.2010v15n30p57/19530>. Acesso em: 2 jul. 2015.

COSTA, L. F. da; SILVA, A. C. P. da; RAMALHO, F. A. (Re)visitando os estudos de usuário: entre a "tradição" e o "alternativo". DataGramaZero, v. 10, n. 4, ago. 2009. Disponível em: <http://www.dgz.org.br/ago09/Art_03.htm>. Acesso em: 28 out. 2014.

CUNHA, M. B. da. Metodologias para estudo de usuários de informação científica e tecnológica. Revista de Biblioteconomia de Brasília, v. 10, n. 2, p. 5-19, jul./dez. 1982.

DERVIN, B.; NILAN, M. Information needs and uses. Annual Review of Information Science and Technology, v. 21, p. 3-33, 1986.

FERREIRA, S. M. S. P. Estudo de necessidades de informação: dos paradigmas tradicionais à abordagem Sense-Making. Porto Alegre: Associação Brasileira de Educação em Ciência da Informação, 1997. Disponível em: <http://pt.scribd.com/doc/6747637/Estudo-deNecessidades-de-InformaCAo>. Acesso em: 21 out. 2014.

FERREIRA, S. M. S. P. Novos paradigmas e novos usuários de informação. Ciência da Informação, [S. I.], v. 25, n. 2, p. 1-10, 1995. Disponível em: $<$ http://bogliolo.eci.ufmg.br/downloads/FERREIRA\%20Novos\%20paradig mas.pdf >. Acesso em: 28 out. 2014.

FIGUEIREDO, N. M. de. Estudos de uso e usuários da informação. Brasília: IBICT, 1994.

GUINCHAT, C.; MENOU, M.. Introdução geral às ciências e técnicas da informação e documentação. Brasília: IBICT, 1994. Disponível em: <http://livroaberto.ibict.br/handle/1/1007>. Acesso em: 02 jul. 2015. 
ALPÍZAR, S.; LIDIETTE DIEZ, M. L. S.; ROJAS, E. Organización de servicios. In: FLORES, L.; CÁCERES, H. Información jurídica: princípios para la organización de bibliotecas em instituciones jurídicas de América Latina. San José: Instituto Latinoamericano de las Naciones Unidas para la Prevención del Delito y el Tratamiento del Delincuente, ILANUD, 1991.

MIRANDA, A. C. de C. de; D'AMORE, T. M.; PINTO, V. B. Gestão documental da informação jurídica. Perspectivas em Ciência da Informação, Belo Horizonte, v. 18, n. 3, p. 96-110, jul./set. 2013.

MONTEIRO, R. N. M.; COSTA, L. F. da; RAMALHO, F. A. Dimensões de qualidade na avaliação da satisfação dos usuários da biblioteca do Tribunal Regional do Trabalho da Paraíba. Revista Brasileira de Biblioteconomia e Documentação, São Paulo, v. 10, n. 1, p. 21-35, jan./jun. 2014. Disponível em: <http://rbbd.febab.org.br/rbbd/article/view/278/287> . Acesso em: 02 jul. 2015.

OLIVEIRA, A. C. C. Biblioteca especializada jurídica: campo de atuação para o profissional bibliotecário. 2013. 62f. Trabalho de Conclusão de Curso (Bacharelado em Biblioteconomia) - Centro Universitário de Formiga, Formiga, 2013.

ORDEM DOS ADVOGADOS DO BRASIL. Institucional: história. 2014. Disponível em: <http://www.oab-sc.org.br/historia>. Acesso em: 18 nov. 2014.

PINHO, F. A.; BARBOSA, Â. M. da S. Os usuários da informação jurídica. Biblios, n. 44, p. 50-61, 2011.

REZENDE, A. P. de; MACHADO, V. M. Centro de informação jurídica eletrônico e virtual. Ciência da Informação, Brasília, v. 29, n. 1, p. 51-60, jan./abr. 2000. Disponível em: <http://revista.ibict.br/ciinf/index.php/ciinf/article/view/264/231>. Acesso em: 31 out. 2014.

SILVA, A. G. Fontes de informação jurídica: conceitos e técnicas de leitura para o profissional da informação. Rio de Janeiro: Interciência, 2010.

SILVA, F. C. C. Bibliotecário especialista: guia de especialidades e recursos informacionais. Brasília: Thesaurus, 2005.

SILVA, J. L. C. Necessidades de informação e satisfação do usuário: algumas considerações no âmbito dos usuários da informação. InCID: Revista de Ciência da Informação e Documentação, Ribeirão Preto, v. 3, n. 2, p. 102-123, jul./dez. 2012. Disponível em: <http://www.revistas.usp.br/incid/article/view/48656/52727>. Acesso em: 28 out. 2014 . 